\title{
SOCIEDADES COMPLEXAS E RISCO ECOLÓGICO - EPISTEMOLOGIA E MEIO AMBIENTE NA ATUAL TEORIA DE SISTEMAS.
}

\author{
SOCIEDADES COMPLEJAS Y RIESGO ECOLÓGICO - EPISTEMOLOGIA E \\ AMBIENTE EN LA TEORIA DE SISTEMAS ACTUAL.
}

\section{COMPLEX SOCIETIES AND ECOLOGICAL RISK - EPISTEMOLOGY AND THE ENVIRONMENT IN THE CURRENT SYSTEMS THEORY.}

\author{
João Júlio Vitral AMARO ${ }^{1}$
}

\begin{abstract}
RESUMO: Pensar a questão do risco ecológico nas sociedades complexas envolve a idéia de sistema e seus conceitos correlatos, como ordem, desordem, complexidade ou irreversibilidade. Abordar a teoria de Niklas Luhmann a partir da pergunta sobre a vulnerabilidade ecológica significa trazer para discussão os conceitos fundamentais de uma teoria social capaz de abordar problemas de outros ângulos, diferentes daqueles cobertos pelas abordagens correntes. A separação da sociedade em sistemas, própria das sociedades funcionalmente diferenciadas, inclui a possibilidade de que cada sistema observe e descreva esses processos e seus riscos inerentes. Como não há um único observador privilegiado, já que a sociedade se observa por intermédio de seus vários sistemas, abrem-se, pela teoria de Luhmann, varias possibilidades de leituras de questões atuais correspondentes à complexidade das sociedades tecnológicas.
\end{abstract}

Palavras chave: teoria de sistemas, teoria social, risco ambiental

RESUMEN: Pensar la cuestión del riesgo ecológico en las sociedades complejas envuelve la idea de sistema y sus conceptos correlativos, como orden, desorden, complejidad e irreversibilidad. Abordar la Teoría de Niklas Luhmann a partir de la pregunta sobre la vulnerabilidad ecológica significa traer a discusión los conceptos fundamentales de una teoría social, capaz de abordar problemas desde otros ángulos, diferentes de aquellos cubiertos por los abordajes corrientes. La separación de la sociedad en sistemas, propia de las sociedades diferenciadas, incluye la posibilidad de que cada sistema observe y describa esos procesos y sus riesgos inherentes. Como no hay un único observador privilegiado, ya que la sociedad se observa por intermedio de sus varios sistemas,

1 Prof. Dr. Associado na Escola de Arquitetura, Universidade Federal de Minas Gerais (UFMG). Doutorado no Departamento (Fachbereich) Umwelt und Gesellschaft -Technische Universitaet, Berlin, Alemanha. Msc. em Economia (UFMG), Teoria Econômica. Especialização em Planejamento Habitacional, Faculdade de Arquitetura da UNB. Graduação em Arquitetura (UFMG). Experiência em Economia, com ênfase em Economia Ambiental e Urbana, atua nos temas: meio ambiente, metodologia da análise ambiental, paisagem urbana, planejamento, avaliação de curso superior e teoria de sistemas. jjvitralamaro@gmail.com 
se abren, por la teoría de Luhmann, varias posibilidades de lecturas de cuestiones actuales correspondientes a la complejidad de las sociedades tecnológicas.

Palabras Claves: Teoria de sistemas, teoría social, riesgo ambiental.

ABSTRACT: To think about the issue of ecological risk in complex societies involves the idea of system and its correlated concepts, such as order, disorder, complexity or irreversibility. Approaching Niklas Luhmann's theory from the query of ecological vulnerability means discussing the fundamental concepts of a social theory that is able to address problems from different points of view, different than those which are discussed on current approaches. The separation of society into systems, a trace of functionally different societies, includes the possibility of each system observing and describing these processes and their inherent risks. Since there is not a sole privileged observer, as society observes itself through its various systems, according to Luhmann's theory, several possibilities of different readings of current issues, which correspond to the complexities of technological societies are opened up.

Keywords: systems theory, social theory, environmental risk

Frente aos riscos ambientais, as sociedades desenvolvem dispositivos para defesa ou reação, de acordo com suas capacidades tecnológicas, o grau de ameaça e a possibilidade de previsão internalizada por experiências passadas de eventos catastróficos. Toda essa capacidade de mobilização depende de características específicas de cada sociedade e, assim, é possível descrever as sociedades por meio da reação aos eventos que rompem com as expectativas de regularidade da vida social. Isso porque todos os recursos mobilizados, como a capacidade tecnológica, a visibilidade de ameaças e a intromissão de experiências passadas no balizamento dos eventos catastróficos indicam o arcabouço por meio do qual as sociedades vêem ou interpretam a si mesmas. Pode-se dizer que uma sociedade é um processamento regular, uma tradução para seus próprios parâmetros das ameaças que estão "fora" dela. Aquilo que está fora dela é decidido por ela mesma; ou ainda, decidir o que está fora é atribuição apenas dela, é uma "construção" que, “correta" ou não, afasta uma programação externa, de fora dos próprios códigos com os quais a sociedade opera.

A sociedade processa em seus próprios códigos, ou melhor, ela é esse processar, esse relacionar consigo mesma em operações próprias das operações cibernéticas. Para a teoria de sistemas, a aproximação do fenômeno social com a cibernética não é apenas um apelo a uma simples analogia. Não são apenas as semelhanças entre máquinas (para nos atermos à referência mais corriqueira quando a palavra cibernética é lembrada) e sociedade que instalam a possibilidade de um mesmo linguajar. As sociedades também operam em sistemas de código e programas e, a 
partir deles, podemos examinar a questão, dentre outras, do risco ambiental e as representações que as várias formas sociais fazem dele. Obviamente que se trata aqui de um processo relacionado com a construção da vida social, com a coesão e permanência de processos que interligam indivíduos em suas várias dimensões, ou, se quisermos adotar ainda o jargão do marxismo, no plano material e ideológico. Esse processar em códigos se distribui por toda a sociedade por seus sistemas (jurídico, econômico, religioso, científico, educacional, artístico, amoroso ou erótico etc.). Para a teoria de sistemas, o sistema econômico (com o processar de seus códigos internos), ao contrário do que pretende a teoria marxista, não é a base a partir da qual todos os outros seriam explicados. Não há sistemas subordinados a outros; e menos ainda uma "esfera pública" (como pretende Habermas) capaz de coordenar ou "programar" todas as outras.

Essa separação da sociedade em sistemas, própria das sociedades modernas, "funcionalmente diferenciadas" (não estratificadas), não exclui, no entanto, a possibilidade de que cada sistema observe, descreva ou busque uma comunicação com outro sistema. Para examinar a questão ambiental e os riscos a ela inerentes, podemos montar uma estratégia de observação de como a sociedade moderna observa a si mesma. Como não há um único observador privilegiado, já que a sociedade se observa por intermédio de seus vários sistemas, cumpriria escolher aqueles que mais elementos trariam para a definição dos rumos que a sociedade escolhe para ver e reagir frente à ameaça ecológica. Se resolvermos começar pelo sistema econômico, teremos a vantagem de examinar de perto a palavra de ordem - "sustentabilidade", já que nesta está embutida uma representação econômica do problema ambiental; quer dizer, a palavra é um núcleo em torno do qual se movem as manifestações de preocupação, predominante e não exclusiva, com o problema alimentar do futuro. Esse problema pode ser lido como problema econômico. É (ou passa a ser) um problema econômico se observadas as operações com as quais as sociedades modernas lidam com as interpretações e soluções da questão ambiental.

A economia ou, melhor dizendo, o discurso da economia (ou ainda, na linguagem da teoria de sistemas, a observação do sistema de ciência sobre o sistema econômico) é um grande reservatório semântico que a sociedade moderna tem para falar de si mesma. Não que a semântica da economia tenda (como quer o marxismo) à hegemonia nas sociedades modernas, dada a suposta prevalência ou a sobredeterminação do econômico sobre as demais esferas da vida social. O que é possível que ocorra nas sociedades modernas é a maior decantação do discurso da economia (ou, numa linguagem mais precisa, das representações que se fazem da economia) no seu distanciamento do discurso religioso; decantação esta que não ocorre na mesma intensidade frente, por exemplo, ao discurso jurídico. O próprio linguajar, corrente em várias esferas da vida social, que se utiliza de 
expressões como "justiça econômica”, "preço justo", “economia solidária” etc., atesta essa contaminação semântica entre sistemas, ou a transposição de códigos de uns sistemas para outros; no caso, para a economia. Não por acaso, as questões ambientais, contidas até então em repertórios de sistemas específicos, é sinalizada no discurso da economia, embora não seja tão nova assim a tematização do desenvolvimento relacionado com os limites materiais impostos pelos recursos naturais.

A mobilização de governos de vários países, de organizações políticas e de cientistas em torno da questão do atendimento das necessidades humanas do futuro têm levado a constatações alarmantes, amplamente partilhadas pela opinião pública mundial, como as teses do Clube de Roma (1972) e o Relatório Brundtland (1987). Esses fóruns mundiais são acontecimentos que assinalam a questão ambiental em escala planetária, colocam no centro da discussão o problema dos limites naturais, do papel do mercado e das inovações tecnológicas para a superação desses limites. Conclusões derivadas das teses do Clube de Roma, por exemplo, apontavam para a necessidade do “crescimento zero" na economia, muito embora não fosse novidade a idéia de "economia em estado estacionário". Projeções e prescrições sobre o crescimento das sociedades podem ser encontradas desde os textos de Platão (República) ou Aristóteles (Política). Quando a economia começa a se consolidar como disciplina autônoma, Adam Smith (1723-1790), por exemplo, expressa seu temor de que um "estado estacionário", ao qual a economia poderia chegar devido à tendência das taxas declinantes dos lucros, comprometeria investimentos futuros. Para ele, nas situações de crescimento (progressive state) todo o corpo social é mais feliz. Ao contrário de Adam Smith, John Stuart Mill (1806-1873) acreditava que a salvação da humanidade estaria em um estado estacionário, sem crescimento (steady-state mankind). A julgar pela diversidade de projeções e prescrições econômicas, o fato de a humanidade ser salva ou não parece depender pouco das leituras que dela faz a economia.

O Relatório Brundtland, ao trazer o conceito de desenvolvimento sustentável, marca uma diferença de perspectiva com relação ao Clube de Roma e aponta mais para o nível, a qualidade, do desenvolvimento econômico. Assim, é colocado no centro da questão ambiental o problema do impacto que a sociedade moderna, altamente técnica, produz sobre o ambiente e as consequiências a médio e longo prazo. A partir de então, desenvolvimento sustentável é entendido mundialmente como "o desenvolvimento que satisfaça as necessidades presentes sem comprometer a capacidade das gerações futuras em satisfazer as suas próprias”. Isso implica manter, para as gerações futuras, o estoque de recursos renováveis (ar, água, flora, fauna etc.) e os recursos naturais não renováveis (combustíveis de origem fóssil, minerais); quer dizer, na idéia de sustentabilidade está subjacente a 
idéia de uma possibilidade de "programação", no presente, do futuro consumo da natureza. O fato de se ter que decidir hoje o futuro metabolismo do homem com o planeta é uma dimensão essencial na consideração que faz Niklas Luhmann sobre o risco na sociedade moderna.

A partir do discurso ambientalista, é observada a prática da economia e seu discurso em seus pressupostos básicos: a substituição entre bens produzidos pelo homem (capital) e bens naturais e a confiança na inovação tecnológica em sempre oferecer uma resposta à escassez dos recursos naturais. Como conseqüência desses pressupostos da teoria econômica, são consagrados os atuais modelos de crescimento econômico, mesmo com recursos escassos, na condição de que esses possam ser substituídos pelo capital, seja pela inovação tecnológica (resource saving), seja pela reciclagem completa. Assim, começando o exame do discurso da economia pelas considerações da natureza física, da materialidade dos bens econômicos, algumas considerações desenvolvidas por Georgescu-Roegen podem ajudar a esclarecer a codificação de um sistema (no caso, da economia), executando aquilo que, na linguagem da teoria de sistema, é chamado de observação de segunda ordem. Como na observação de um sistema pelo outro ou na decodificação de um sistema por outro, chaves interpretativas são acionadas e abertas outras leituras que escapam ao sistema em exame. É o que acontece, por exemplo, quando Georgescu-Roegen, físico e economista, afirma que a economia deve ser examinada a partir da teoria termodinâmica. O núcleo fundamental da observação da economia pela física termodinâmica é a idéia de tempo, pois, no formalismo dos modelos da economia, está o tempo reversível da mecânica clássica. Para Georgescu-Roegen, é surpreendente que a teoria econômica tenha adotado o modelo mecanicista quando a mecânica clássica não tinha mais o domínio absoluto na física. A evidência dos modelos mecanicistas é a representação, comum nos livros de economia, do processo econômico como um diagrama circular, um movimento pendular entre a produção e o consumo em um sistema completamente fechado. Isso até então não era considerado um problema, mas com a termodinâmica fica mais evidente que a economia trabalha com uma restrita concepção de tempo, pois, para a física clássica, é indiferente se o tempo é um valor positivo ou negativo. Isso significa que, por mais que a economia faça projeções, sua possibilidade de acertar o quadro econômico do futuro é bastante incerta.

Parece ser a intenção de Georgescu-Roegen a atualização conceitual, a "dinamização" da teoria para fazê-la corresponder à própria dinâmica da natureza. A palavra termodinâmica é de origem grega - significa movimento do calor e dá nome à teoria do início do século XIX relacionada com a eficiência dos motores térmicos. Sadi Carnot, seu primeiro teórico, faz uma análise do funcionamento de uma máquina térmica ideal. Seu experimento consistiu em considerar uma máquina perfeitamente reversível, ou seja, isenta de perdas de calor, demonstrando como a 
eficiência se relaciona com a passagem do calor de um corpo quente para um corpo frio; ou, no caso de uma máquina a vapor, como o calor passa de uma câmara quente (onde o calor se forma) para uma câmara fria (onde se condensa). Assim, a diferença entre as duas câmaras é responsável pelo bom desempenho da máquina e, mesmo no caso de uma máquina idealizada, a eficiência de $100 \%$ jamais é alcançada. Com isso, Carnot demonstra que o rendimento termodinâmico tem um limite teórico que não pode ser ultrapassado. Tal conclusão tem uma extensão teórica e prática que vai muito além do domínio das máquinas a vapor. Outro teórico da termodinâmica, Clausius, distinguiu processos reversíveis de processos irreversíveis, introduzindo o conceito de entropia: uma grandeza que aumenta com a dissipação e atinge o seu valor máximo quando todo o potencial de executar trabalho está esgotado. No caso da máquina a vapor, a máxima entropia designa a desordem, a mistura quente-frio ou a não-diferença entre as temperaturas das duas câmaras, impossibilitando o trabalho. De acordo com essa versão da teoria, em um processo reversível a variação de entropia é nula, ao passo que, nos processos irreversíveis, a entropia sempre aumenta. A partir desse princípio (conhecido como o segundo princípio da termodinâmica) fica aberta para o discurso ambientalista a possibilidade de se afirmar que o problema com o qual a humanidade se confronta não é prioritariamente o da conservação da energia, mas o da conservação de uma certa qualidade de dote energético, de capacidade de fornecer trabalho. Isso porque, a partir do segundo princípio, a energia existe em dois estados qualitativos: a energia disponível e a energia não disponível. Essa distinção, que, mesmo para a física, é assumidamente antropomórfica, diz que a energia química contida em um pedaço de carvão, por exemplo, é energia disponível para o homem, para a transformação em calor e daí em trabalho mecânico em substituição ao dispêndio da força (biológica) do trabalho humano. A imensa energia calorífica do mar é energia não disponível, jamais será aproveitada na produção de trabalho. A energia disponível implica uma estrutura ordenada, encontrável na natureza, como o carvão, ou organizada pelo homem, como usinas nucleares.

Desse modo, pode-se dizer que a entropia se define também como uma medida de ordem/desordem. De acordo com Georgescu-Roegen, para quem os princípios da termodinâmica devem se aplicar na consideração econômica da transformação material, uma lâmina de ferro apresenta menor entropia que o mineral que a produziu. A lamina de ferro, matéria organizada, presta-se mais diretamente ao uso humano do que o ferro em estado bruto. Mas, nessa transformação material, a natureza cobra um preço: a organização da matéria é também uma desorganização, um aumento da entropia. Para Georgescu-Roegen, a dissipação ou degradação da matéria-energia (dos elementos dispostos pela natureza) segue uma rota de irreversibilidade que é acelerada pela produção humana: uma folha de papel (matéria organizada) apresenta uma entropia 
mais baixa do que a massa de celulose, com a qual a sua produção se iniciou. Mas esse aumento de ordem (a baixa entropia da folha de papel) só foi possível porque, em algum lugar, a entropia (desordem) aumentou na forma de dispersão de energia dos trabalhadores e das máquinas e de dejetos líquidos, de gases na atmosfera. A constatação de que a entropia proporciona uma "flecha do tempo" explícita - ou seja, a entropia crescente coincide com o movimento do tempo para frente - vem fazer com que os modelos reversíveis da economia sejam questionados como modelos que possam apreender a degradação ou dissipação da matéria/energia presente em todas as dimensões do processo econômico em geral (produção, transporte, consumo etc.).

Coincidem com o crescimento vertiginoso da organização material - ou seja, com a transformação dos bens naturais de seu estado bruto para formas da matéria organizada e orientada para os fins humanos - as representações de ameaça, perigo ou risco que as sociedades complexas fazem de si mesmas. Em parte pela alta dosagem de realismo político ou pelo imobilismo teórico dos estrategistas das políticas econômicas dos países industrializados, a geração de energia em usinas nucleares e as manipulações genéticas na produção de alimentos aparecem como caminhos inevitáveis ao que se entende por desempenho econômico. A alta tecnocracia, aliada aos portavozes da racionalidade econômica (leia-se: do imperativo ao aumento de produtividade), encontra, no entanto, obstáculos para efetivar seus modelos de desempenho. Grande parte da opinião pública mundial, ou pelo menos aquela parte que mais tem visibilidade na mídia, está sempre dando o tom aos ruidosos protestos, à verbalização sobre os riscos no uso de tecnologias avançadas. A recusa veemente das tecnologias inovadoras acontecia antes mais por motivos religiosos, morais ou ideológicos. Hoje a idéia de risco é o que mobiliza corações e mentes, muito embora, para as manifestações atuais, seja trazida uma antiga distinção, explícita ou não, entre natureza e técnica.

Contrariando um tipo de representação supostamente ecológica da sociedade moderna, é conveniente, do ponto de vista da exploração teórica do problema, abandonar a cisão naturezatécnica em proveito de uma abordagem que não seja simplesmente associar a natureza ao bem e a técnica ao mal. Uma sugestão de um outro conceito ou abordagem da questão da técnica é apontada por Niklas Luhmann para se examinar a questão do risco: a técnica é "a simplificação funcional num dado conjunto de relações causais". Para examinar melhor a idéia de risco e a de técnica aí subjacente, é necessária a exploração de algumas idéias centrais de Luhmann e, mais especificamente, aquela que caracteriza sua teoria social frente às outras teorias de sistema: o conceito de autopoiesis.

Para descrever processos relacionados à neurofisiologia, Maturana, biólogo chileno, adotou o neologismo autopoiesis, que rapidamente se difundiu pela vertente epistemológica do 
construtivismo, com destaque na teoria de sistema. Maturana examina processos cognitivos a partir do funcionamento do cérebro. $\mathrm{O}$ cérebro funciona em regime de clausura operacional; quer dizer, não é "programável" de fora; suas operações são uma autoprodução. Isso ocorre nos sistemas biológicos em geral e pode ser ilustrado pela vida de uma célula, como o faz Francisco Varela, outro biólogo que trabalha em estreita cooperação com Maturana. Pode-se entender que uma célula é o menor sistema vivo; isto é, uma organização que preserva a si mesma como resultado de sua organização. Isso quer dizer que ela produz componentes que produzem componentes que produzem componentes: enzimas produzem enzimas. O limite da célula é sua membrana. A membrana é o processo que limita a difusão e assim preserva a rede de produção que produz a membrana. E, como já expressou Varela, em todos os lugares podem-se ver sistemas que existem devido a uma espécie de efeito Münchausen; quer dizer: eles tiram a si mesmos do pântano, puxando-se pelos próprios cabelos. Essa imagem vale para processos distintos; embora recorrente quando se trata do conceito de vida, a autopoiesis (biológica) é apenas um exemplo. A teoria de sistema oferece outros exemplos como linguagem, famílias, firmas ou organizações.

Assim, a teoria de sistemas sociais incorpora o conceito de autopoiesis, ampliando suas possibilidades de descrição da sociedade. Do mesmo modo que os sistemas vivos são caracterizados pela autopoiesis, também os sistemas psíquicos e os sistemas sociais se individualizam na sua autoreferência: nos processos psíquicos, pensamentos são feitos de pensamentos e nos processos sociais comunicação é feita de comunicação. A comunicação é a operação específica que identifica os sistemas sociais: não existe sistema social que não tenha como operação própria a comunicação, e não existe comunicação fora dos sistemas sociais. Como toda a comunicação é uma operação interna a um sistema social, entre os sistemas sociais e seu entorno não há comunicação. Como sua autoprodução é exclusivamente comunicação, os sistemas sociais, encerrados em si mesmos, não se comunicam com o entorno. Um sistema social, no entanto, é aberto ao entorno; mas a condição de abertura é dada pela sua clausura operacional, pela comunicação auto-referenciada: o entorno se constitui comunicativamente, como informação, como tema da comunicação social.

A transposição do conceito de autopoiesis do contexto biológico para o social não significa que uma analogia ou semelhança de sistemas orgânicos e sociais seja afirmada. A generalização e especificação, retradução do conceito de autopoiesis, quer dizer, sua reaplicação em um caso especial pela teoria de Luhmann permite mesmo que sistemas vivos, neuronais, sistemas psíquicos, assim como sistemas sociais, sejam conceituados como unidades que, de acordo com sua autopoiesis, cada uma do seu modo, se diferenciem. Todos esses sistemas são autopoiéticos, organizados segundo sua autopoiesis, mas não se dissolvem num metassistema, nem permitem que 
se aponte uma hierarquia de sistemas. Sistemas nervosos, sistemas psíquicos e sistemas sociais formam diferentes ordens que, segundo o princípio da autopoiesis, mantêm entre si a relação de ambiente, entorno, uns para os outros. É conveniente lembrar que a palavra usada por Luhmann para designar o entorno de um sistema é a palavra alemã Umwelt, que também é traduzida entre nós por ambiente. Embora a palavra alemã Umwelt seja usada como usamos "meio-ambiente" na língua portuguesa, no sentido de ecologia; o Umwelt como o "outro" do sistema é mais amplo, pode designar meio-ambiente como também tudo aquilo "fora" do sistema.

O entorno ou o ambiente (Umwelt) de um sistema se constitui simultaneamente ao sistema; não há sistema sem ambiente, nem ambiente sem sistema. $\mathrm{O}$ ambiente, enquanto tal, não é um sistema específico; ele é tudo mais que não o sistema para o qual ele é ambiente. Os termos sistema e ambiente são complementares; o sistema não existe enquanto tal, mas apenas na distinção, na diferença frente àquilo que não é ele. Essa diferença é dada pelo código interno ao programa do sistema. O código é a forma com a qual o sistema diferencia a si mesmo do ambiente e organiza sua clausura operacional. Na comunicação cientifica (ou no operar do sistema ciência), por exemplo, a diferença se define frente ao entorno (no caso, a sociedade) pelo código verdadeiro/não verdadeiro.

A afirmação do sistema enquanto sistema, sua demarcação ou afirmação de diferença frente ao entorno, envolve suas operações de "decodificação" da complexidade do ambiente ou, lembrando a teoria da termodinâmica, corresponde à criação da baixa entropia, à criação da ordem ou a diminuição da complexidade. A complexidade de uma unidade indica o fato de que nem todos os elementos da unidade podem estar todos ao mesmo tempo, simultaneamente com eles mesmos. A partir de uma analogia com a termodinâmica, Claude Shannon desenvolve a teoria da informação, ampliando o conjunto de elementos hoje usados pela teoria de sistemas. Assim, conceitos de complexidade, ordem, organização e informação qualificam um sistema e dão a medida da informação potencial nele contida: quanto mais informação potencial contida em um sistema, mais informação ele terá. Assim, a noção de complexidade se presta ao exame do grau de informação potencial. Um sistema complexo consiste de grande parte de elementos distintos que se relacionam entre si espacial e temporalmente. Quanto mais existe tal estruturação entre elementos e quanto maior o número de elementos, mais informação é necessária para identificar toda a estrutura em seus componentes independentes e, do mesmo modo, maior a informação que se obtém de tal estrutura. A idéia de ordem, em contraposição à de complexidade, não se relaciona a estados potenciais, mas à situação existente no tempo e no espaço: um sistema será mais ordenado quanto mais se puder atribuir a ele uma regularidade espacial (como acontece, por exemplo, em um cristal) ou temporal (como as oscilações periódicas de um pêndulo). Ordem relaciona-se, portanto, à 
redução dos estados potenciais de um sistema. A ordem máxima é então obtida quando a informação atual existente - e não a informação potencial - se torna máxima; ou ainda, quando a entropia do sistema se torna mínima. Graus de ordem podem se expressar como graus de liberdade de um sistema: um sistema possui diversos graus de liberdade que, por meio da ordem, podem ser reduzidos.

Desse modo, a complexidade significa que é necessária uma seleção para atualizar as relações entre os elementos. A distinção entre elemento e relação é o fundamento da definição de complexidade. A complexidade pode ser observada em um sistema ou em seu entorno, mas apenas a complexidade de um sistema é complexidade organizada. Esta consiste nas relações seletivas entre os elementos do sistema: é a organização seletiva da autopoiesis. O número de relações possíveis entre os elementos de um sistema aumenta exponencialmente em relação ao aumento do número de elementos mesmos. Isso significa que, quando os elementos se tornam muito numerosos, o número de relações alcança um tamanho que não é mais controlável pelo próprio sistema, o que indica que nem todo sistema pode atualizar-se e colocar-se em relação simultaneamente. Complexidade é o fato de que existem mais possibilidades do que a capacidade de que todas venham a se realizar; as interações entre os elementos são possíveis se consideradas individualmente para cada elemento, mas as interações de todos com todos pode não ser suportável, pode congestionar o sistema. A seletividade impede o colapso das unidades complexas.

Em um sistema social, nem tudo pode estar atualizado; são feitas reduções a partir da necessidade de se manter uma complexidade interna que se faça compatível o sistema com relação ao entorno. Redução de complexidade significa que uma estrutura de relações entre elementos (de um sistema ou do entorno) se reconstrói em um número menor de relações em um sistema particular. A complexidade se realiza e se mantém em um sistema só mediante reduções. Sendo assim, redução e manutenção da complexidade se necessitam mutuamente. Redução de complexidade significa a permanência seletiva num conjunto de possibilidades em bases estruturais. São as estruturas que determinam quanta complexidade interna um sistema pode criar e tolerar. As estruturas são condições que delimitam o âmbito de relação das operações de um sistema; são as condições de autopoiesis do sistema. O conceito de estrutura indica, portanto, a seleção das relações entre elementos admitidos em um sistema. Com a ênfase no conceito de estrutura não se deve, no entanto, considerar a teoria de Luhmann estruturalista ou funcional-estruturalista; ela é muito mais uma teoria que tem como centro o conceito de evento (Ereignis), mais próxima dos chamados pósestruturalistas. 
Quando observada por um sistema, a complexidade, como apontado acima, escapa a uma consideração abstrata, objetiva; ela apenas é complexidade frente a uma operação de seletividade: uma unidade é complexa apenas como produto de uma observação - e observação é operação de um sistema. O sistema se autodiferencia, demarca-se frente ao entorno filtrando, "vendo" apenas aquilo que ele pode processar. Se o sistema não vê tudo do entorno, já que o entorno apresenta maior complexidade do que a capacidade de processamento pelo sistema, está colocada a possibilidade de tematização do risco pelo sistema: o risco é o resultado da observação feita pelo sistema social sobre aquilo que representa uma ameaça ao seu funcionamento enquanto sistema. Esta é, no entanto, uma ameaça não totalmente delineada. É uma ameaça que se processa pelo sistema.

Considerando uma sociedade que, por algum de seus sistemas, observa a si mesma, delimitando seu entorno na comunicação sobre, por exemplo, abastecimento alimentar, as conseqüências da teoria podem ser mais bem ilustradas. Essa observação da sociedade sobre si mesma significa, na linguagem corrente, que a referida sociedade, em algum nível, tematiza o problema alimentar; não significando com isso que toda a sua complexidade se reduza à questão da alimentação. Sua complexidade interna, no entanto, vai filtrar a complexidade do entorno na tentativa de extrair daí soluções para o seu problema de abastecimento. Seu entorno será de um tipo se for uma sociedade sem nenhum conhecimento tecnológico e será de outro tipo se sua tecnologia for capaz de aumentar a produtividade natural do solo: para o mesmo solo natural dois entornos diferentes, pois são duas distinções diferentes. O desenvolvimento tecnológico amplia a possibilidade do entorno em proveito do sistema social. Essa tecnologia é, no entanto, o filtro a partir do qual a complexidade do entorno será reduzida ou processada. A redução da complexidade significa, no entanto, o aumento da complexidade interna ao sistema. A produção alimentar será feita por uns meios (tecnológicos) e não por outros (abandonando parte da complexidade do entorno), e a decisão sobre os meios escolhidos aumentará a complexidade interna do sistema social: redução de complexidade é, para o sistema, aumento de complexidade. Assim, a partir da exploração dos conceitos da cibernética desenvolvida por Niklas Luhmann, é possível considerar de novos ângulos a questão do risco ambiental. A rigor, Luhmann não especifica o tipo de risco tratado em sua teoria como risco ambiental exclusivamente. Mas como a caracterização do risco não é exclusiva de um conjunto de fatos assemelhados que são interpretados como ameaça, mas se estende à consideração do entorno (ambiente) da vida social, os conceitos aí elaborados podem ser trazidos para o exame da questão ambiental ou ecológica.

O sistema (ou um dos sistemas da sociedade) pode distinguir risco pela codificação binária "risco/segurança", na distinção do risco enquanto situação outra que não a segurança. Essa é, no 
entanto, uma distinção banal, pouco capaz de estimular a exploração do tema; e talvez por sua trivialidade favoreça os discursos dos políticos quando querem se passar pelos depositários da segurança pública. Luhmann propõe a distinção "risco/perigo" como aquela mais apta para desenvolver o tema risco nas sociedades complexas. Como na teoria de sistema as distinções são feitas por observadores, é possível que, para a grande maioria, para as (potenciais) vítimas, as (possíveis) catástrofes apareçam como perigo, como fatalidades, como um processar de leis naturais impossível de ser previsto. Para os tomadores de decisão, para os que mobilizam técnicas de previsão ou de prevenção, as conseqüências das decisões aparecem como risco. Não se trata aqui de uma dramatização da relação culpados/vítimas, na qual os tomadores de decisão seriam os culpados por decisões erradas. A questão tratada por Luhmann é mais sutil e aponta para características únicas das sociedades modernas dotadas de crescente sofisticação tecnológica: as decisões são imprescindíveis. As sociedades estão tão entranhadas pela alta tecnologia que o simples fato de se renunciar a uma decisão é também uma decisão.

Luhmann distingue grande tecnologia de alta tecnologia. A primeira diz respeito aos problemas de sobrecarga, do dimensionamento, dos problemas de gestão que derivam do funcionamento de redes ferroviárias, redes de abastecimento, linhas telefônicas, redes de comunicação em geral etc., coisas sem muito interesse frente à questão da técnica como redução funcional, como imposição incontornável do aumento da complexidade social. A alta tecnologia diz respeito ao emaranhamento da tecnologia no interior dos sistemas sociais que torna obrigatória sempre a decisão sobre a tecnologia, mas já no interior das possibilidades prescritas pela própria tecnologia. Não há caminho de volta. Uma vez tendo-se decidido pela redução da complexidade (na escala elevada exigida pela alta complexidade social), pela baixa entropia da matéria organizada e dirigida a fins específicos, menos chance haverá para caminhos alternativos. É como se fossem trilhos a estar sempre em construção, cujas bitolas são definidas de antemão (por uma decisão anterior) e, portanto, excluindo outras, para suportar um corpo que se move inapelavelmente sempre para frente. A tecnologia como simplificação orientada para um fim, como decisão sobre umas e não outras das tantas relações causais, significa não apenas o necessário abandono de possibilidades, mas o enquadramento das possibilidades futuras. Toda decisão relacionada à alta tecnologia envolve risco. A decisão sobre geração de energia por usinas nucleares leva o problema da atividade radioativa dos dejetos para, no mínimo, mil anos à frente. A decisão em não se ter usina nuclear entrega também ao futuro o problema da escassez de recursos para a geração de energia. Por isso, a descontinuidade na representação do tempo é, de acordo com Luhmann, uma característica das sociedades modernas. O futuro não está lá adiante, num fluxo contínuo onde está 
também o presente, como parece ter sido na idéia de tempo das gerações passadas, mas é o resultado de decisões que se tomam para um futuro que será tão mais improvável quanto maior for o grau de redução da complexidade imposta pela tecnologia.

\section{BIBLIOGRAFIA}

BECK, U. Risikogesellschaft - Auf dem Weg in eine andere Moderne. Frankfurt am Main: Suhrkamp Verlag, 1986.

GEORGESCU-ROEGEN, N. The entropy law and the economic process. London: Harvard University Press, 1999.

LUHMANN, N. Oekologische Kommunikation. Wiesbaden: Verlag fuer Sozialwissenschaften, 2004.

LUHMANN, N. Soziologie des Risikos. Walter de Gruyter: Berlin, 2003.

LUHMANN, N. Die Wissenschaft der Gesellschaft. Frankfurt am Main: Suhrkamp Verlag, 1992.

LUHMANN, N. Soziale Systeme. Frankfurt am Main: Suhrkamp Verlag, 1987.

MATURANA, H. A ontologia da realidade. Belo Horizonte: Editora UFMG, 2002.

PERROW, C. Normal accidents. Princeton: New Jersey, 1999.

VARELA, F.Kognitionswissenschaft - Kognitionstechnik. Frankfurt am Main: Suhrkamp Verlag, 1990. 